\title{
Development of the experimental stand for investigation of heating and drying phenomena in the porous building materials with one surface of the sample exposed to the flowing air
}

\author{
Łukasz Cieślikiewicz ${ }^{1 *}$, Piotr Łapka ${ }^{1}$, Michat Wasik $^{1}$, Michat Kubiś ${ }^{1}$, Karol Pietrak ${ }^{1}$, Tomasz S. Wiśniewski ${ }^{1}$, \\ Piotr Furmański ${ }^{1}$, and Mirosław Seredyński ${ }^{1}$ \\ ${ }^{1}$ Institute of Heat Engineering, Faculty of Power and Aeronautical Engineering, Warsaw University of Technology, 21/25 Nowowiejska \\ Street, 00-665 Warsaw, Poland
}

\begin{abstract}
The paper presents development of the experimental stand for investigation of heating and drying phenomena in the porous building materials with one surface of the sample exposed to the flowing air. Moreover, results of preliminary measurements which verify the range of operating conditions achieved by the stand are shown. These conditions were assumed in the following range: $15^{\circ} \mathrm{C}-60^{\circ} \mathrm{C}, 10-90 \%$ and 0.1 $10 \mathrm{~m} / \mathrm{s}$ for temperature, relative humidity and velocity of the flowing air, respectively. In order to control the parameters of air used for heating and drying of porous materials, a closed-loop concept of the stand was proposed and equipped with several elements, i.e., the cooler (vapour condenser), fan with variable rotational speed, humidifier and heater. Furthermore, two parallel measurement ducts which allow to obtain two air streams with identical parameters were proposed. This enables two measurements at one time as well as faster verification of the repeatability of the performed measurements. The temperature measurements at the top surface and inside the sample are carried out applying the IR thermography and several K-type thermocouples, respectively, while overall moisture amount and the moisture content distribution in the specimen are found using tensometric force and electrical resistance meters, respectively.
\end{abstract}

\section{Introduction}

The amount of moisture in building materials is highly important for building structure. In porous building materials water might come from many sources, e.g., due to rising of the groundwater level, rain or condensation of water vapour from the humid air. The water in building structure degenerates its thermal insulation and mechanical properties. Biological corrosion and salts decay are also observed [1-3]. Moreover, it influences the indoor microclimate conditions as well as affects the comfort of the occupants and their health [4]. Moisture in building materials might be accumulated for a long time, especially in historical buildings $[5,6]$. Due to these problems, drying and renovation of walls are required in many buildings.

The drying process in porous media is present not only in building materials but also, i.e., in food processing, paper production, crops drying and garments. Wide range of different types of dried porous media constitutes large area for complex research of the drying phenomena. Studies concerning various types of material (e.g., brick, cloth, food, etc.) and applying the same experimental stand and setup for investigation of the drying process in different materials were not reported in the literature.

Generally, drying process might be categorised in the following main groups:
- Convective drying [7-11];

- Vacuum drying [11];

- Microwave drying [10, 12-14].

Mathematical description of the drying process is characterised by high level of complexity and is based on complex partial differential equations. In practical cases these equations are combined with fluid and heat flow equations and could not be solved analytically. Therefore, numerical models which involve Computational Fluid Dynamics (CFD) to simulate combined heat, mass and fluid flow in moist porous materials [15-20] are developed. These models take into consideration each phase (i.e., vapour, liquid water, dry air, solid phase) separately or collectively by balancing the moisture in the material [15-17]. Numerical models allow to compute the moisture transfer assuming either the equilibrium state between vapour and liquid water or the local non-equilibrium state [15-20]. The wide range of models with different assumptions and different but equivalent systems of equations should be be validated and compared for the same conditions in the speciallydesigned validation experiments. The influence of modelling assumptions on calculated results and their matching with experimental measurements should be analysed.

In order to analyse the drying process, different experimental stands were developed which accounted for

\footnotetext{
Corresponding author: lukasz.cieslikiewicz@,itc.pw.edu.pl
} 
different drying mechanisms. In case of existing buildings, most important is the convective drying in which moisture and heat transfer between the flowing air and sample depends on the local flow conditions, i.e., temperature, relative humidity and velocity of the air [3]. For this reason, the ranges of air flow parameters influence the designs of the experimental stands. For example, the experiments might be conducted in the free convection conditions or with low-velocity forced convection in a climatic chamber [21-23]. For highspeed forced convection, special wind ducts are built. These ducts are of either open flow [8, 16, 24] or closedloop [3] type. Experiments described in the literature were conducted with air flow velocities up to $5 \mathrm{~m} / \mathrm{s}$ [3, $16]$ and relative humidity as high as $35 \%$ and $44 \%$.

The paper presents development of the experimental stand with a closed-loop concept and two parallel measurement ducts for the investigation of heating and drying phenomena in porous building materials. Only one surface of the sample is exposed to the flowing air. The operating conditions of the stand were assumed in the following range: $15^{\circ} \mathrm{C}-60^{\circ} \mathrm{C}, 10-90 \%$ and $0.1-10 \mathrm{~m} / \mathrm{s}$ for temperature, relative humidity and velocity of the flowing air, respectively. The preliminary stability tests and drying measurements have been carried out and the obtained results are shown in this work.

\section{Experimental stand}

\subsection{Main assumptions of the stand}

The designed stand meets several requirements. Majority of them were related to the parameters of the working fluid (air), i.e., its temperature, relative humidity and velocity. These parameters were assumed and controlled in the following range: $15^{\circ} \mathrm{C}-60^{\circ} \mathrm{C}, 10-90 \%$ and $0.1-$ $10 \mathrm{~m} / \mathrm{s}$, respectively. Additionally, in order to obtain the data for the validation of numerical models developed in parallel, following different parameters in dried material are measured:

- Temperature distribution on the surface of the sample;

- Temperature distribution within the specimen;

- The global amount of moisture;

- Moisture content distribution within the specimen.

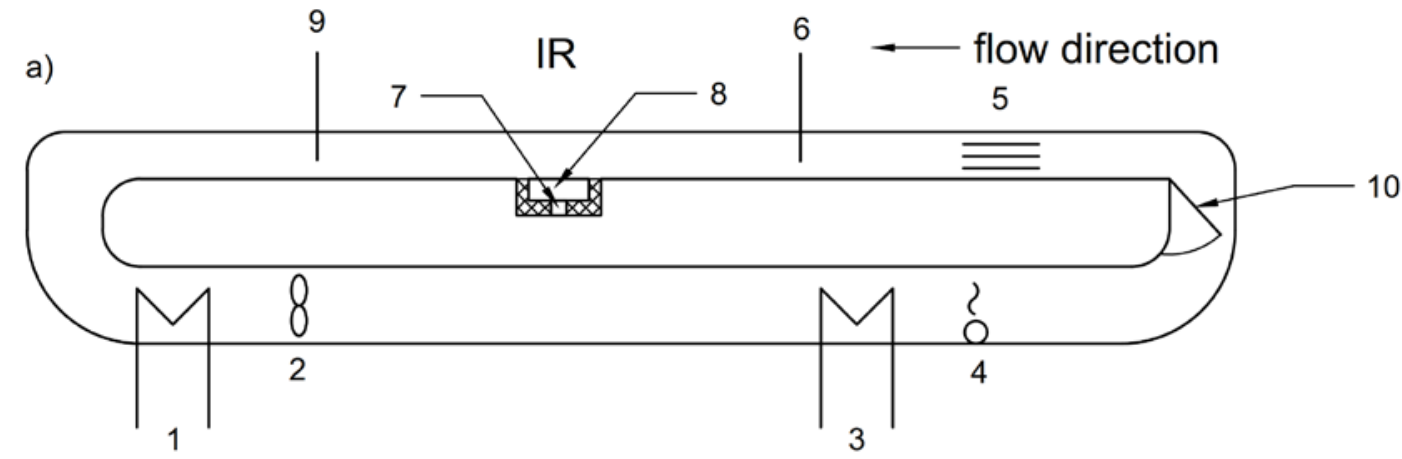

b)

\begin{tabular}{|llll|}
9 & 8 & 6 & 5 \\
\hline$\circ$ & $\circ$ & $\equiv$ \\
\hline$\circ$ & & $\equiv$ & $\equiv$ \\
\hline
\end{tabular}

c)

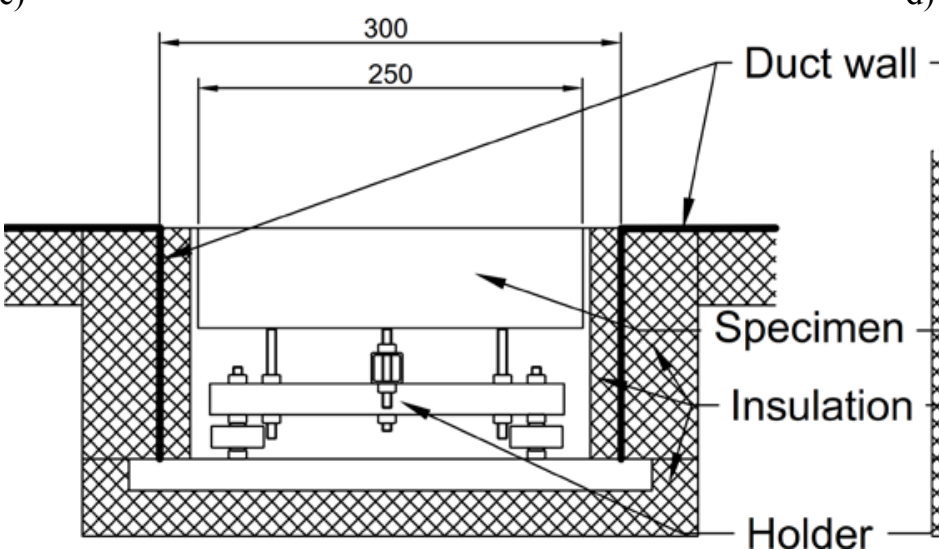

d)



Fig. 1 Simplified schematic of the closed-loop flow experimental stand: a) side and b) top view as well as cross-section of specimen pocket with main dimensions: c) side and d) perpendicular to the flow direction view. 


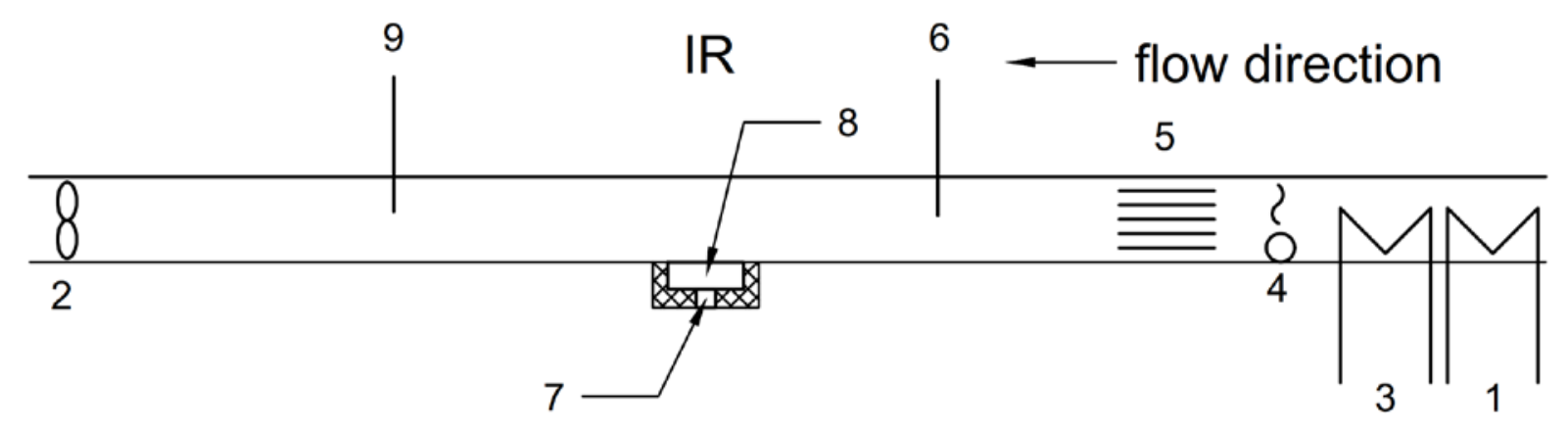

Fig. 2. Simplified schematic of the open-flow experimental stand.

\subsection{Main concept of the stand}

During design of the experimental stand, two main concepts were initially considered, i.e.:

- Closed-loop flow (Figure 1);

- Open flow (Figure 2).

In both cases, the system consisted of the following elements (numbers listed below refer to respective numbers in Figures 1 and 2):

1. Cooler/condenser;

2. Fan;

3. Heater;

4. Humidifier;

5. Flow stabilizer;

6. Integrated velocity, temperature and humidity transmitter;

7. Force meter;

8. Sample;

9. Integrated temperature and humidity transmitter;

10. Throttle.

Figures 1 and 2 graphically present both concepts (closed- and open-loop stands) and their elements denoted by numbers from 1 to 10 . The closed-loop stand includes two parallel channels which allow to take simultaneously two measurements in the same conditions (see Figure 1c and d).

Finally, the closed-loop flow concept was chosen for further development. The major advantages of this concept in comparison with the open-flow stand concept are following:

- Lower power required by the heater, cooler and humidifier as well as the ability to achieve operational parameters in few cycles. In case of the open flow concept, the operating conditions have to be achieved immediately which could be problematic for high mass flow rates of air.

- Lower dependence of the measured parameters on the conditions of the surroundings.

- The ability to investigate two specimens in identical conditions at the same time - see Figure 1.

- Lower space requirements due to location of some elements of the stand (i.e., cooler/condenser, fan, heater and humidifier) under measurement ducts - see Figure 1.

- Better ability to control and stabilise parameters of the working air used for drying samples. This also refers to obtaining more reliable results which might be applied then in the validation of the numerical models.


Fig. 3. Cross-sections of segments: two square ducts with stabilisers (upper) and round duct (bottom) with dimensions.

\subsection{Development of the stand}

The experimental stand was made as modular construction. The stand consists of two segments of the duct, i.e., round at the bottom and square, split into two identical ducts, on top (see Figure 1). Figure 3 presents dimensions of both segments of the duct. The outermost modules connect the top and bottom segments of the duct and therefore consist of two $90^{\circ}$ bends and roundto-rectangular connector. All air conditioning equipment is located in the bottom segment (see elements no. 1-4 in Figure 1). In the first module, cooler/condenser (1) and fan (2) are placed. The cooler/condenser is made of a copper pipe twisted into a spiral and connected to a refrigerated circulation bath with glycol. This solution allows for both air cooling in case of measurements at low temperatures as well as removal of the excessive amount of the moisture and reduction of the relative humidity of air to assumed level. The cooler is mounted shortly before the fan which protects it from overheating. The fan, with rotation speed controlled by a frequency inverter, allows for smooth changing of the air velocity 
from $4.3 \mathrm{~m} / \mathrm{s}$ up to $10 \mathrm{~m} / \mathrm{s}$. In order to reduce the flow velocity to the desired range (i.e., $0.1-4.3 \mathrm{~m} / \mathrm{s}$ ), a throttle (10) located in the third module or an additional flow resistance in the duct might be used. Additionally, in the front of first module power, control and safety elements are mounted. In the third module electrical heater (3) of power equal to $3 \mathrm{~kW}$ and humidifier (4) are located. The humidifier consists of a pipe with a gap at lower pressure side, connected with a tank with mist. Mist is produced by an ultrasonic piezoelectric mist generator. To stabilize and homogenize the flow field after the round-torectangular connector and throttle, the stabilizer (5) was applied. The stabilizer was made as an array of several small rectangular ducts (cross-section dimeters of $25 \times 30 \mathrm{~mm}$ ) of length equal to $300 \mathrm{~mm}$ placed inside both measurement ducts as shown Figure 3.

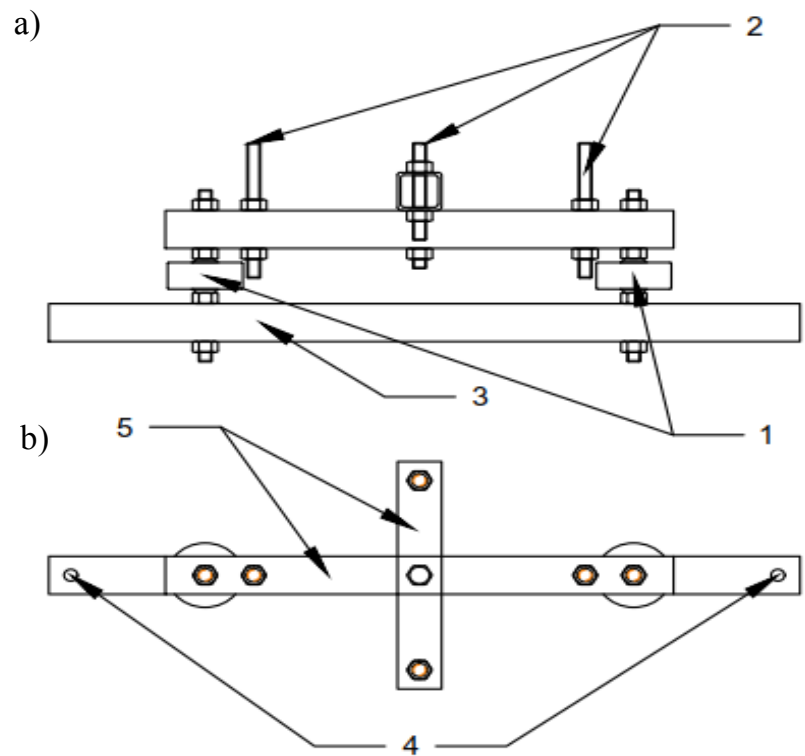

Fig. 4. Sample holder with force meters for configuration with air flow above the specimen: a) side and b) top view (where numbers denote: 1 - force meters, 2 - regulation rods, 3 - base, 4 - assembly holes and 5 - support profiles).

The top segment of the middle module contains the pocket for the specimen (8) and force meters (6) with the sample holder which allows to level and position the sample (see Figure 1c and d). Figure 4 presents schematic views of this holder. In order to stiffen its construction and enable the measurement of sample's mass, two axial force meters (see element no. 1 in Figure 4) were applied. The holder allows for utilisation of samples of different sizes by adjustment of the specimen level using the regulation system (2). This system was made of four threaded rods and screws, mounted to the support profiles (5). The support profiles were connected to the base (3) by the force meters. The whole construction was assembled to the stand using screws and assembly holes (4). The bottom and lateral surfaces of the specimen pocket were surrounded by insulation made of the expanded polystyrene foam. The small air gap between insulation and specimen was left to prevent the insulation from affecting on the measurement of the sample mass. The gap was closed on the top side by a metallic tape. The top surface of the specimen was aligned with the tape and duct's wall.

The position of the specimen in the duct might be changed, i.e., from bottom to either lateral or top by rotation of the duct in order to investigate the influence of the gravitational acceleration on the drying process. In the case with the air flowing above the specimen, gravitational acceleration has small influence on the liquid water transfer in the porous medium. But for cases with lateral air flow or flow under the specimen, gravitational acceleration has significant influence on the process. In these cases, liquid water is transferred to the surface of the sample and comes into direct contact with the flowing air. The air flow around the sample in the lateral configuration is the closest to the real wall drying process. The holder presented in Figure 4 was modified in order to allow for changing of the sample position from bottom to either lateral or top.

\subsection{Acquisition and control}

The acquisition and control of different parameters in the stand is crucial for its proper operation. In order to measure the parameters of air and the specimen, special sensors were utilised. An integrated temperature, relative humidity and velocity as well as integrated temperature and humidity transmitters were applied for measurements of the air flow parameters (see elements no. 6 and 9 in Figure 1). The temperature map on the top surface of the sample was obtained by the IR thermography. Only one camera was used and measurements were taken with frequency from 2 to 6 samples per hour which allow to change position of camera between two measurement ducts. The disturbing effects of water vapour present in the air flowing in the ducts were taken into account during IR measurements. Moreover, K-type sheath thermocouples of $0.5 \mathrm{~mm}$ diameter were applied for measurements of temperature variation in the material of the sample. The global moisture content was found gravimetrically with two tensometric force meters per sample (see elements no. 7 and 1 in Figure 1 and 4, respectively). The distribution of moisture content on the surface of the sample might be also estimated from the temperature distribution obtained with the IR thermography. Moreover, a system of individually calibrated resistance meters was applied and now a new method of measurements of moisture distribution in the sample is being developed and tested. In order to enable data processing and storage, all signals were converted from analog to digital in a multifunction data acquisition (DAQ) device connected with a computer with dedicated in-house software developed in the LabView environment. The DAQ device is equipped with digital outputs which were used to control the solidstate relay and regulate the parameters inside the experimental stand. Sampling frequency was set to 0.5 $\mathrm{Hz}$. 


\section{Test measurements}

\subsection{Stability measurements}

In order to verify the stability of the controlled parameters of air in the stand (i.e., temperature, relative humidity and velocity of the air) several test measurements were conducted. The standard deviation and difference from the mean value were principal indicators applied for the parameters stability verification. Table 1 contains experimentally-obtained values of stability indicators while Figures 5-7 present variations of controlled parameters.

The results shown in Table 1 and Figures 5-7 prove that obtained stability of the controlled parameters (i.e. temperature, relative humidity and velocity of the air) is very high.

Table 1. Stability indicators for the air parameters.

\begin{tabular}{|l|c|c|c|}
\hline \multirow{2}{*}{ Indicator } & Temperature & $\begin{array}{c}\text { Relative } \\
\text { humidity }\end{array}$ & Velocity \\
\cline { 2 - 4 } & {$\left[{ }^{\circ} \mathrm{C}\right]$} & {$[\%]$} & {$[\mathrm{m} / \mathrm{s}]$} \\
\hline $\begin{array}{l}\text { Standard } \\
\text { deviation }\end{array}$ & 0.035 & 0.13 & 0.12 \\
\hline $\begin{array}{l}\text { Maximum spread } \\
\text { from mean }\end{array}$ & 0.108 & 0.51 & 0.39 \\
\hline
\end{tabular}

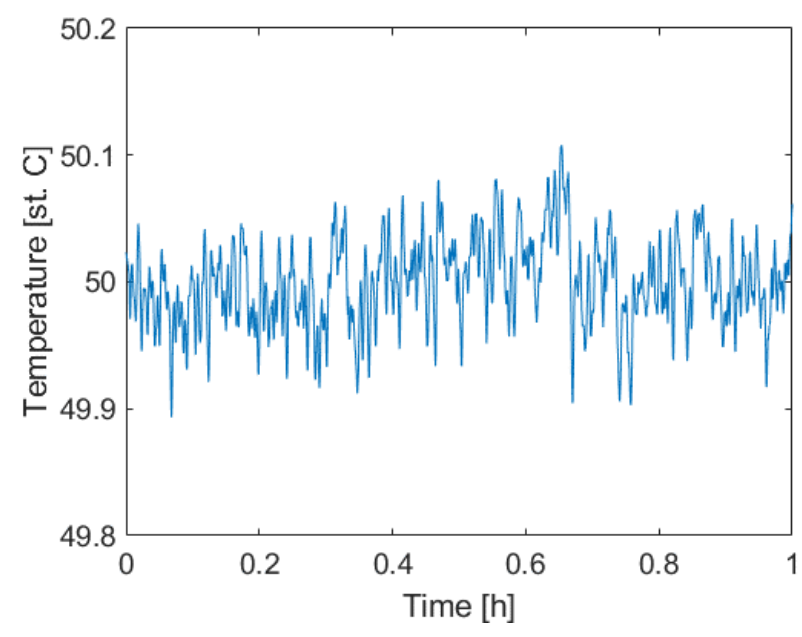

Fig. 5. Variation of the temperature of air flowing in the stand.

\subsection{Drying tests}

The functional correctness of the stand was verified in several measurements. Figures 8 and 9 present results for drying of the whole ceramic brick with initial moisture content of $13.5 \%$ wt. During the measurements, air temperature, relative humidity and velocity were equal to $50^{\circ} \mathrm{C}, 20 \%$ and $10 \mathrm{~m} / \mathrm{s}$, respectively. Before the measurements the specimen was conditioned, i.e., it was fully-submerged in water for 24 hours in order to obtain initial high content of moisture. The water used to saturate the sample was taken from the water pipe system and had the conductivity and hardness of $1000 \mu \mathrm{S} / \mathrm{cm}$ and $4 \mathrm{mval} / \mathrm{l}$, respectively. Before being placed in the duct, the specimen has been wiped from excessive water.

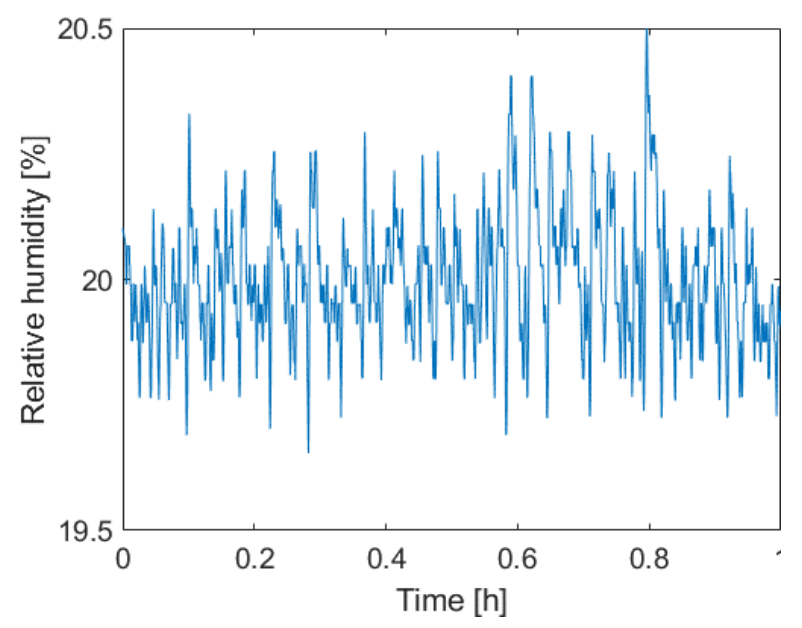

Fig. 6. Variation of the relative humidity of air flowing in the stand.



Fig. 7. Variation of the velocity of air flowing in the stand.

The locations of thermocouples in the sample were as follows (see Figure 8b):

- T1 - middle of the sample, $5 \mathrm{~mm}$ deep from the bottom surface;

- T2, T3 - $6 \mathrm{~cm}$ from the front and rear edges, respectively, in half width of the sample, $5 \mathrm{~mm}$ deep from the bottom surface;

- T4, T5 $-3 \mathrm{~cm}$ from the side edges in half length of the sample, $5 \mathrm{~mm}$ deep from the bottom surface.

The temperature variation during drying of the sample for different locations is presented in Figure 8a. The first stage of drying resulted in achieving of saturation conditions. This stage was characterized by fast water evaporation from the sample surface and reduction of the moisture content in the sample (see Figure 9). Later, in the second stage, increase of the sample temperature towards the air flow temperature was observed (see Figure 8).

The temperature distributions on the top surface of the specimen at different stages of drying are also presented in Figure 10. It was found that the location of the drying front is strongly connected with temperature 
distribution. Saturation temperature and the front proceed together with the flow direction, i.e., from right to left side. After the evaporation of the liquid water, the sample temperature started to increase.

Figure 8 and 10 revealed existing gradient of temperature and moisture content in the direction perpendicular to the flow of air in the duct. This effect may be related to both non-uniform initial distribution of the moisture in the brick and capillary forces in the brick which results in the moisture movement to the wall of the sample. The sides walls of the sample were well insulated and water proof.

a)



b)

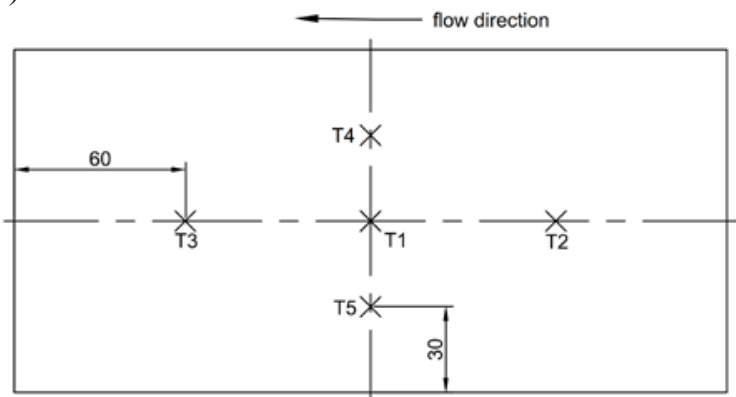

Fig. 8. a) Variations of temperature at different locations in the specimen dried by air of temperature $50^{\circ} \mathrm{C}$, relative humidity $20 \%$ and velocity $10 \mathrm{~m} / \mathrm{s}, \mathrm{b}$ ) cross-section of the specimen with locations of thermocouples.

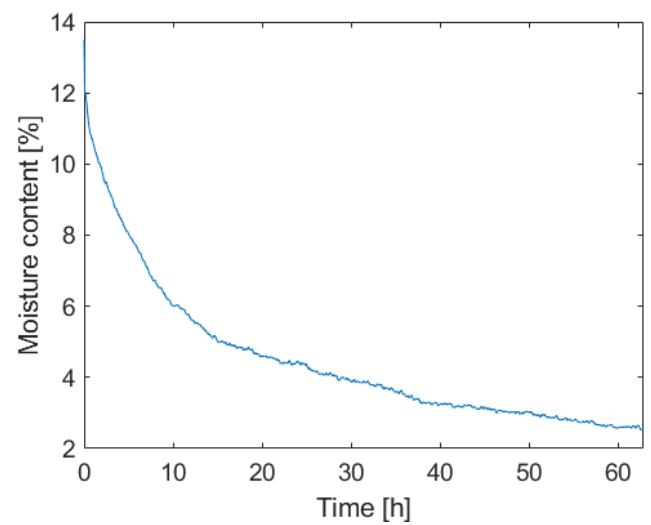

Fig. 9. Variation of the total moisture content in the specimen dried by air of temperature $50^{\circ} \mathrm{C}$, relative humidity $20 \%$ and velocity $10 \mathrm{~m} / \mathrm{s}$.

\section{Conclusions}

The paper presents the development of the experimental stand with closed-loop flow and two parallel measurement ducts for investigation of heating and drying phenomena in porous building materials. Only one surface of the sample is exposed to the flowing air. The operating conditions of the stand were assumed in the following range: $15^{\circ} \mathrm{C}-60^{\circ} \mathrm{C}, 10-90 \%$ and $0.1-10 \mathrm{~m} / \mathrm{s}$ for temperature, relative humidity and velocity of the flowing air, respectively. These ranges are wider than those encountered in the literature. Good stability of controlled parameters was obtained during verification measurements which indicates that the stand is ready for future experiments designed to validate numerical and analytical models which are developed in parallel. The change of sample location from bottom to either lateral or top gives the opportunity to study the influence of gravitational acceleration on drying phenomena. Additionally, the wide range of operating conditions achieved in the stand allows for the investigation of drying process of different materials, i.e., food, crops or waste. a)



c)

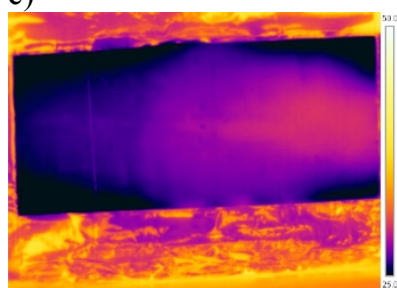

e)



g)

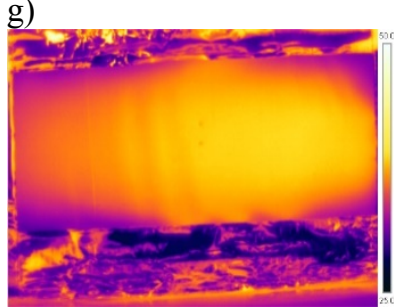

b)

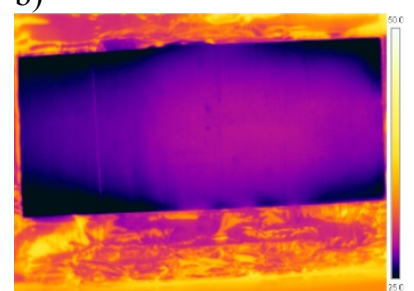

d)



f)

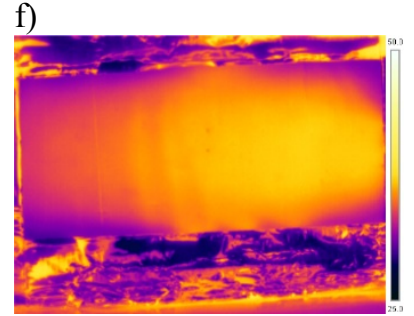

h)

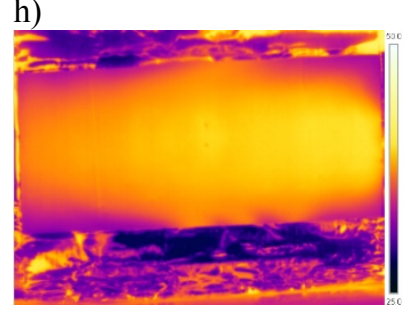

Fig. 10. Temperature distributions at the top surface of the specimen after: a) $10 \mathrm{~min}, \mathrm{~b}) 1 \mathrm{~h}$, c) $3 \mathrm{~h}$, d) $6 \mathrm{~h}$, e) $12 \mathrm{~h}$ and f) $24 \mathrm{~h}$ g) $48 \mathrm{~h}$ and h) $72 \mathrm{~h}$ for drying air at temperature of $50^{\circ} \mathrm{C}$, relative humidity of $20 \%$ and flow velocity of $4.3 \mathrm{~m} / \mathrm{s}$. The minimum and maximum temperatures on thermographs are $25^{\circ} \mathrm{C}$ and $50^{\circ} \mathrm{C}$, respectively. 


\section{Acknowledgements}

This work was supported by the National Centre for Research and Development (Poland) under grant no. POIR.04.01.02-00-0099/16 Development of innovative technology of drying and moisture sealing of masonry walls, DryWall.

\section{References}

1. P.B. Lourenço, E. Luso, M.G. Almeida, Build. Environ. 41, 223-234 (2006)

2. M. Trochonowicz, Bud. i Archit. 7, 131-144 (2010)

3. N. Karagiannis, M. Karoglou, A. Bakolas, M. Krokida, A. Moropoulou, Constr. Build. Mater. 137, 441-449 (2017)

4. R.C. Shoemaker, D.E. House, Neurotoxicol. Teratol. 28, 573-588 (2006)

5. L. Falchi, D. Slanzi, E. Balliana, G. Driussi, E. Zendri, Build. Environ. 131, 117-127 (2018)

6. A.M. Gueli, V. Garro, M. Liuzzo, G. Margani, S. Pasquale, G. Politi, G. Stella, Meas. J. Int. Meas. Confed. 118, 289-297 (2018)

7. J.R. de J. Junqueira, J.L.G. Corrêa, H.M. de Oliveira, R. Ivo Soares Avelar, L.A. Salles Pio, LWT - Food Sci. Technol. 82, 404-410 (2017)

8. A.M. Castro, E.Y. Mayorga, F.L. Moreno, J. Food Eng. 223, 152-167 (2018)

9. I. Boutelba, S. Zid, P. Glouannec, A. Magueresse, S. Youcef-ali, Data Br. 18, 1567-1575 (2018)
10. I. Das, A. Arora, J. Food Eng. 223, 208-219 (2018)

11. B. Zecchi, L. Clavijo, J. Martínez Garreiro, P. Gerla, J. Food Eng. 104, 49-55 (2011)

12. L. Kurik, T. Kalamees, U. Kallavus, V. Sinivee, Energy Procedia. 132, 159-164 (2017)

13. G. Cuccurullo, L. Giordano, A. Metallo, L. Cinquanta, Biosyst. Eng. 170, 24-30 (2018)

14. J. Szadzińska, S.J. Kowalski, M. Stasiak, Int. J. Heat Mass Transf. 103, 1065-1074 (2016)

15. X. Cheng, J. Fan, Int. J. Therm. Sci. 43, 665-676 (2004)

16. M. Van Belleghem, M. Steeman, H. Janssen, A. Janssens, M. De Paepe, Build. Environ. 81, 340-353 (2014)

17. J. Fan, X. Wen, Int. J. Heat Mass Transf. 45, 40454055 (2002)

18. P. Salagnac, P. Glouannec, D. Lecharpentier, Int. J. Heat Mass Transf. 47, 4479-4489 (2004)

19. L. Pel, K.A. Landman, E.F. Kaasschieter, Int. J. Heat Mass Transf. 45, 3173-3180 (2002)

20. V.A.F. Costa, M.L. Mendonça, A.R. Figueiredo, Int. J. Heat Mass Transf. 51, 3342-3354 (2008)

21. J. Zheng, J. Shi, Q. Ma, X. Dai, Z. Chen, Appl. Therm. Eng. 114, 450-456 (2017)

22. Y. Zhang, X. Luo, X. Wang, K. Qian, R. Zhao, Atmos. Environ. 41, 3203-3216 (2007)

23. M. Bianchi Janetti, L.P.M. Colombo, F. Ochs, W. Feist, Int. J. Therm. Sci. 114, 271-280 (2017)

24. H. Janssen, G.A. Scheffler, R. Plagge, Int. J. Heat Mass Transf. 98, 141-149 (2016) 